\title{
Structural Characterization of (Diphenylhydrazido)vanadium(V) Compounds
}

Takashi Sakuramoto, Toshikazu Hirao, Toshiyuki Moriuchi

\begin{tabular}{|c|l|}
\hline Citation & ChemistrySelect, 2(23): 6618-6622 \\
\hline Issue Date & $2017-08-11$ \\
\hline Type & Journal Article \\
\hline Textversion & Author \\
\hline $\begin{array}{c}\text { Supporting } \\
\text { Information }\end{array}$ & Supporting Information is available at https://doi.org/10.1002/slct.201700833 \\
\hline Rights & $\begin{array}{l}\text { This is the peer reviewed version of the following article: Takashi Sakuramoto, } \\
\text { Toshikazu Hirao, Toshiyuki Moriuchi. (2017). Structural Characterization of } \\
\text { (Diphenylhydrazido)vanadium(V) Compounds. ChemistrySelect,2(23): 6618-6622, } \\
\text { which has been published in final form at https://doi.org/10.1002/slct.201700833 . This } \\
\text { article may be used for non-commercial purposes in accordance with Wiley Terms and } \\
\text { Conditions for Self-Archiving. }\end{array}$ \\
\hline DOI & \begin{tabular}{l} 
10.1002/slct.201700833 \\
\hline
\end{tabular}
\end{tabular}

\author{
Self-Archiving by Author(s) \\ Placed on: Osaka City University
}

Takashi Sakuramoto, Toshikazu Hirao, Toshiyuki Moriuchi (2017). Structural Characterization of (Diphenylhydrazido)vanadium(V) Compounds. ChemistrySelect,2(23): 6618-6622.

https://doi.org/10.1002/slct.201700833 


\title{
Structural Characterization of (Diphenylhydrazido)vanadium(V) Compounds
}

\author{
Takashi Sakuramoto, ${ }^{[a]}$ Toshikazu Hirao, ${ }^{*[a]}$ and Toshiyuki Moriuchi*[a]
}

\begin{abstract}
Diphenylhydrazido)vanadium $(\mathrm{V})$ triisopropoxide was synthesized by the reaction of $\mathrm{VO}\left(\mathrm{O}^{\prime} \mathrm{Pr}\right)_{3}$ with $\mathrm{N}, \mathrm{N}$-diphenylhydrazine. The $\mu$-isopropoxido-bridged dimeric structure was observed in the molecular structure of (diphenylhydrazido)vanadium(V) triisopropoxide. The near-linear $\mathrm{V}(1)-\mathrm{N}(1)-\mathrm{N}(2)$ angle of $173.7(3)^{\circ}$ with the $\mathrm{V}(1)-\mathrm{N}(1)$ distance of $1.667(4) \AA$ indicates that the imido nitrogen has large participation of an sp-hybridized character. The phenyl substituents of the hydrazido moiety were found to conjugate with the $\mathrm{N}-\mathrm{N}$ bond. Furthermore, $\mathrm{CH}-\pi$ intermolecular interaction between two benzene rings was observed to induce polymeric structure in a solid state. (Diphenylhydrazido)vanadium(V) nitrilotriethoxide was obtained by the treatment of (diphenylhydrazido)vanadium $(\mathrm{V})$ triisopropoxide with $2,2^{\prime}, 2$ "-nitrilotriethanol. The slightly increased imido angle (V(1)$\left.\mathrm{N}(1)-\mathrm{N}(2), \quad 176.4(5)^{\circ}\right)$ was observed as compared with (diphenylhydrazido)vanadium( $\mathrm{V}$ ) triisopropoxide probably because of the apical coordination of the nitrogen.
\end{abstract}

\section{Introduction}

Hydrazido compounds $\left(\mathrm{M}=\mathrm{N}-\mathrm{NR}_{2}\right)$ with a metal-nitrogen multiple bond are regarded as important intermediates in organic transformations such as hydrohydrazination and related organic reactions. ${ }^{[1]}$ Considerable attention has been attracted to the structural characterization of hydrazido compounds. Vanadium compounds are known to play a crucial role in a biological process. The inslinomimetic properties of vanadium compounds have been investigated. ${ }^{[2]}$ Also, vanadium haloperoxidases mimicking systems have been reported. ${ }^{[3]}$ However, hydrazido compounds of vanadium have attracted less attention ${ }^{[4]}$ On the other hand, the construction of well-organized molecular arrangements in a solid state has been receiving much interest in the field of crystal engineering. ${ }^{[5]}$ The controlled transition-metal-directed assembly to induce self-organized nanostructures is important for development of functional materials. ${ }^{[6]}$ Alkoxide ligands are known to play an important role in the self-association of vanadium $(\mathrm{V})$ compounds through $\mu$-alkoxido-bridging. ${ }^{[7]} \quad$ Although (imido)vanadium(V) alkoxides with vanadium-nitrogen multiple bond have been demonstrated to dimerize through $\mu$-alkoxidobridging, self-assembling properties of hydrazido compounds of vanadium $(\mathrm{V})$ with alkoxide ligands have not been studied

[a] T. Sakuramoto, Dr. T. Moriuchi, Prof. Dr. T. Hirao Department of Applied Chemistry, Graduate School of Engineering Osaka University

Yamada-oka, Suita, Osaka 565-0871 (Japan)

Fax: (+81) 6-6879-7415

E-mail: moriuchi@chem.eng.osaka-u.ac.jp hirao@chem.eng.osaka-u.ac.jp

Supporting information for this article is available on the WWW underhttp://dx.doi.org/ extensively. Recently, alkoxide ligands of (dimethylhydrazido)vanadium( $\mathrm{V}$ ) have been demonstrated to regulate the self-association properties through the control of coordination environment, wherein isopropoxide ligands were found to induce a $\mu$-isopropoxido-bridged dimeric structure with a trigonal-bipyramidal geometry although a monomeric tetrahedral structure was observed in the case of tert-butoxide ligands. ${ }^{[8]}$ Substituents on the hydrazido moiety of (hydrazido)vanadium(V) alkoxides is envisioned to affect the electronic and steric properties of the vanadium-nitrogen multiple bond, and selfassembling properties. However, the substituent effect of (hydrazido)vanadium( $(\mathrm{V})$ alkoxides on the self-assembling properties has not been investigated so far. We have already performed a unique molecular arrangement of (arylimido)vanadium(V) alkoxides through $\mathrm{CH}-\pi$ interaction. ${ }^{[9]}$ In this context, we embarked upon the elucidation of the aromatic substituent effects on the hydrazido moiety of (hydrazido)vanadium( $V$ ) alkoxides in vanadium-nitrogen multiple bond and the self-assembling properties.

\section{Results and Discussion}

(Diphenylhydrazido)vanadium(V) triisopropoxide (1) was obtained by the treatment of $\mathrm{VO}\left(\mathrm{O}^{\prime} \mathrm{Pr}\right)_{3}$ with $\mathrm{N}, \mathrm{N}-$ diphenylhydrazine in the presence of $\mathrm{NaH}$ as a base in dichloromethane at room temperature (Scheme 1). To reveal the effect of apical coordination, 2,2',2"-nitrilotriethanol, which has three oxygens and one nitrogen working donor sites as a tetradentate ligand, was focused on as a basal ligand. The introduction of 2,2',2"-nitrilotriethoxide ligand was performed by the ligand exchange reaction of 1 with 2,2',2"-nitrilotriethanol in dichloromethane at room temperature, resulting in the formation of (diphenylhydrazido)vanadium( $\mathrm{V}$ ) nitrilotriethoxide (2). The structures of the thus-obtained (diphenylhydrazido)vanadium(V) compounds were elucidated by ${ }^{1} \mathrm{H}$ NMR, ${ }^{13} \mathrm{C}$ NMR, ${ }^{51} \mathrm{~V} \mathrm{NMR}$, and $\mathrm{X}$-ray crystallographic analyses.

The structures of the (diphenylhydrazido)vanadium( $(\mathrm{V})$ compounds were characterized by a single-crystal X-ray structure analysis to elucidate the effect of alkoxide ligands on the coordination environment of the vanadium metal (Table 1). The selected bond lengths and angles are summarized in Table 2 . The molecular structure of 1 with isopropoxide ligands was found to contain a hydrazido structure with the $\mathrm{V}(1)-\mathrm{N}(1)$ distance of 1.667(4) $\AA$, the $\mathrm{N}(1)-\mathrm{N}(2)$ distance of 1.349(5) $\AA$, and the almost linear $\mathrm{V}(1)-\mathrm{N}(1)-\mathrm{N}(2)$ angle of $173.7(3)^{\circ}$ as depicted in Figure $1 \mathrm{a}$. These results suggest that the nitrogen of the $\mathrm{V}-\mathrm{N}$ bond has an sp-hybridized character. The $\mathrm{N}(1)-\mathrm{N}(2)$ distance of $\mathbf{1}$ is longer 


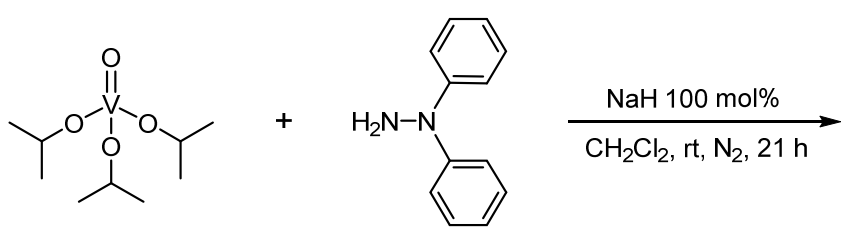

$80 \mathrm{~mol} \%$<smiles>CC(C)OP(=NN(c1ccccc1)c1ccccc1)(OC(C)C)OC(C)C</smiles>

1

$100 \mathrm{~mol} \%$<smiles>CC(C)OP(=NN(c1ccccc1)c1ccccc1)(OC(C)C)OC(C)C</smiles>

1

2

Scheme 1. Synthesis of the (diphenylhydrazido)vanadium(V) compounds $\mathbf{1}$ and $\mathbf{2}$.

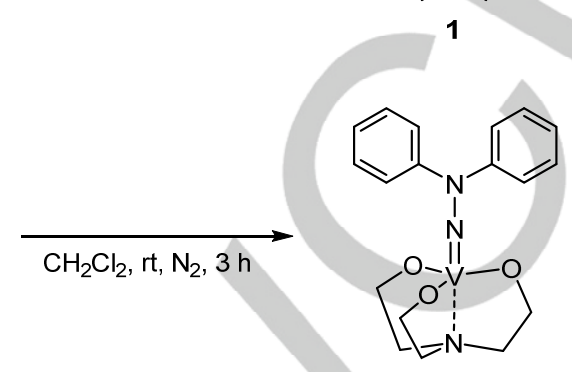

$\mathrm{CH}_{2} \mathrm{Cl}_{2}, \mathrm{rt}, \mathrm{N}_{2}, 3 \mathrm{~h}$

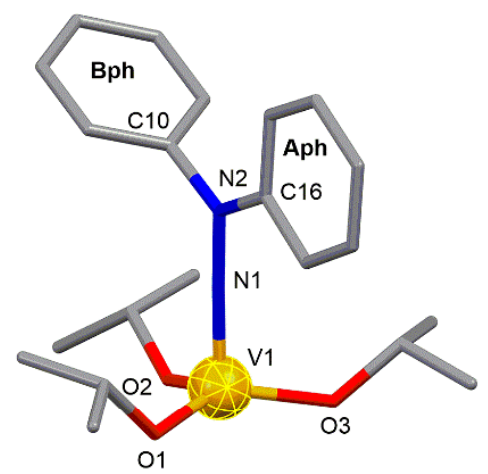

(a)

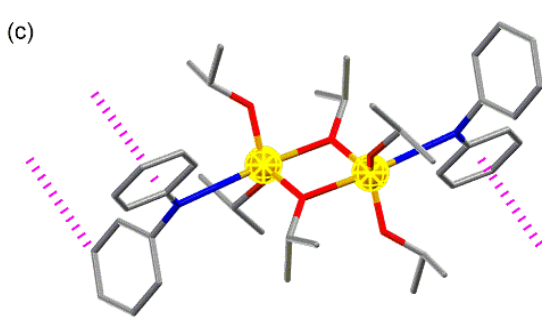

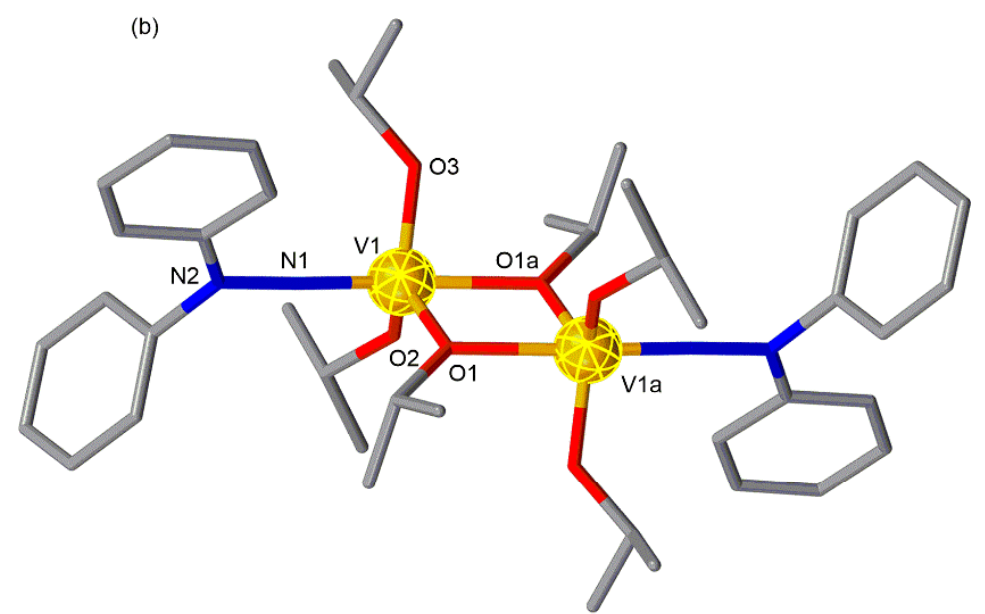

(b)

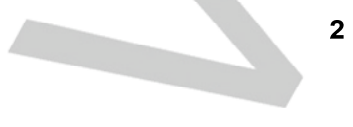

\section{(}


each vanadium atom is coordinated in a distorted trigonalbipyramidal geometry $\left(\tau_{5}=0.77\right)^{[10]}$ with the hydrazido and bridging isopropoxide ligands in apical positions (Figure 1b). The longer apical V(1)-O(1a) distance of 2.157(2) $\AA$ than the equatorial $\mathrm{V}(1)-\mathrm{O}(1)$ distance of $1.888(3) \AA$ in the bridging isopropoxy group

Table 1. Crystallographic date for 1 and 2.

\begin{tabular}{lll}
\hline & $\mathbf{1}$ & $\mathbf{2}$ \\
\hline Empirical formula & $\mathrm{C}_{21} \mathrm{H}_{31} \mathrm{~N}_{2} \mathrm{O}_{3} \mathrm{~V}$ & $\mathrm{C}_{18} \mathrm{H}_{22} \mathrm{~N}_{3} \mathrm{O}_{3} \mathrm{~V} \cdot$ \\
& & $\mathrm{CH}_{2} \mathrm{Cl}_{2}$ \\
Formula weight & 410.43 & 464.26 \\
Crystal system & monoclinic & triclinic \\
Space group & $\mathrm{C} 2 / \mathrm{c}(\mathrm{No} .15)$ & $P-1(\mathrm{No} .2)$ \\
$a(\AA)$ & $23.1167(17)$ & $7.6952(5)$ \\
$b(\AA)$ & $13.3213(8)$ & $10.7153(5)$ \\
$c(\AA)$ & $18.1804(12)$ & $13.8785(6)$ \\
$\alpha\left({ }^{\circ}\right)$ & & $102.419(1)$ \\
$\beta\left({ }^{\circ}\right)$ & $123.9046(15)$ & $93.492(2)$ \\
$\gamma\left({ }^{\circ}\right)$ & & $108.209(2)$ \\
$V\left(\AA^{3}\right)$ & $4646.6(5)$ & $1051.45(9)$ \\
$Z$ & 8 & 2 \\
$D_{\text {calcd }}\left(\mathrm{g} \mathrm{cm}{ }^{-3}\right)$ & 1.173 & 1.466 \\
$\mu(\mathrm{Mo} \mathrm{K \alpha})\left(\mathrm{cm}^{-1}\right)$ & 4.470 & 7.499 \\
$T\left(^{\circ} \mathrm{C}\right)$ & 4.0 & 4.0 \\
$\lambda(\mathrm{Mo} \mathrm{K \alpha})(\AA)$ & 0.71075 & 0.71075 \\
$R 1^{[\mathrm{laj}}$ & 0.0614 & 0.0645 \\
$w R 2{ }^{[\mathrm{b}]}$ & 0.1906 & 0.2265 \\
\hline
\end{tabular}

[a] $R 1=\Sigma|| F_{0}|-| F_{c}|| \Sigma\left|F_{0}\right| .[b] w R 2=\left[\Sigma w\left(F_{0}^{2}-F_{c}^{2}\right)^{2} / \Sigma w\left(F_{0}^{2}\right)^{2}\right]^{1 / 2}$. was observed due to the weaker apical coordination of isopropoxide ligand to the vanadium metal. The ${ }^{1} \mathrm{H}$ NMR spectrum of 1 in $\mathrm{CD}_{2} \mathrm{Cl}_{2}$ showed only one kind of isopropyl resonance, suggesting that 1 is considered to exist in a monomeric structure in a solution state. The $V(1)-V(1 a)$ distance of 3.2603(8) $\AA$ implies the absence of any bonding interaction. Furthermore, each $\mu$-isopropoxido-bridged dimer is connected by continuous $\mathrm{CH}-\pi$ interaction between the benzene ring Aph of one molecue and Bph of the adjacent molecule to form onedimensional polymeric structure in a crystal packing as displayed in Figure 1c. Herein, the distance between the meta hydrogen atom of the benzene ring Bph and the benzene ring Aph is $3.0 \AA$.

A single-crystal $X$-ray structure analysis of $\mathbf{2}$ with nitrilotriethoxide ligand revealed the hydrazido structure, wherein the compound has a pseudo-trigonal-bipyramidal geometry $\left(\tau_{5}=\right.$ $0.98)^{[10]}$ at the vanadium metal due to coordination of the nitrilotriethoxide nitrogen at an apical site as shown in Figure 2a. In this pseudo-trigonal-bipyramidal geometry, vanadium atom is deviated from the plane constituted by an equatorial nitrilotriethoxide oxygen atoms in the direction of the hydrazido moiety. The hydrazido structure showed the near-linear $V(1)$ $\mathrm{N}(1)-\mathrm{N}(2)$ angle of $176.4(5)^{\circ}$ with the $\mathrm{V}(1)-\mathrm{N}(1)$ distance of 1.693(5) $\AA$ and the $\mathrm{N}(1)-\mathrm{N}(2)$ distance of 1.333(6) $\AA$, wherein the nitrogen atom of the $\mathrm{V}-\mathrm{N}$ bond is indicated to be an sp-hybridized character. The donor ability of the apical nitrilotriethoxide nitrogen caused the longer $\mathrm{V}(1)-\mathrm{N}(1)$ bond distance of $\mathbf{2}$ compared with $\mathbf{1}$.

(a)

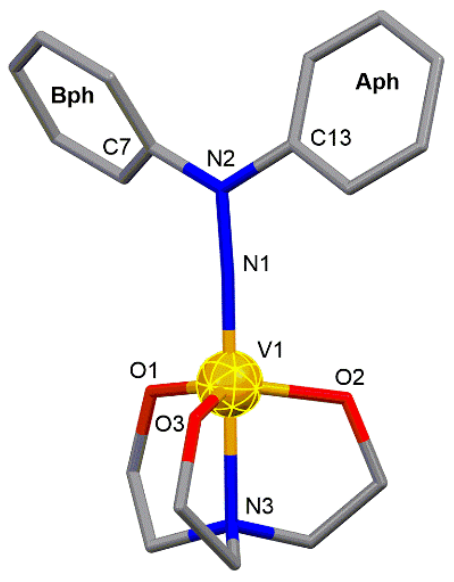

(b)

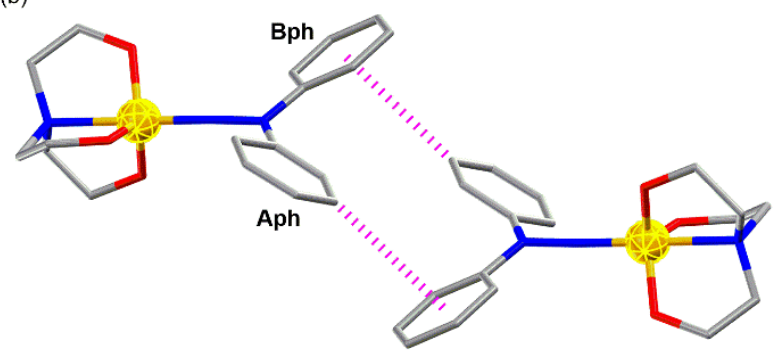

Figure. 2 (a) Molecular structure and (b) the dimeric structure of 2 (hydrogen atoms are omitted for clarity).

\begin{tabular}{|c|c|c|}
\hline & 1 & 2 \\
\hline \multicolumn{3}{|l|}{ Bond Lengths } \\
\hline V1-N1 & $1.667(4)$ & $1.693(5)$ \\
\hline V1-N3 & & $2.188(4)$ \\
\hline V1-O1 & $1.888(3)$ & $1.826(4)$ \\
\hline V1-O2 & $1.773(3)$ & $1.833(5)$ \\
\hline V1-O3 & $1.801(2)$ & $1.834(5)$ \\
\hline V1-O1a ${ }^{\text {[a] }}$ & $2.157(2)$ & \\
\hline N1-N2 & $1.349(5)$ & $1.333(6)$ \\
\hline \multicolumn{3}{|l|}{ Bond Angles } \\
\hline V1-N1-N2 & $173.7(3)$ & $176.4(5)$ \\
\hline N1-V1-N3 & & $179.7(2)$ \\
\hline N1-V1-O1 & $96.40(16)$ & $99.00(19)$ \\
\hline N1-V1-O2 & $102.45(15)$ & $99.1(3)$ \\
\hline N1-V1-O3 & $98.23(12)$ & $98.5(2)$ \\
\hline $\mathrm{N} 1-\mathrm{V} 1-\mathrm{O} 1 \mathrm{a}^{[\mathrm{a}]}$ & $167.98(17)$ & \\
\hline N3-V1-O1 & & $80.65(16)$ \\
\hline N3-V1-O2 & & $81.08(19)$ \\
\hline N3-V1-O3 & & 81.61(17) \\
\hline O1-V1-O2 & $115.92(13)$ & $121.2(2)$ \\
\hline O1-V1-O3 & $122.07(12)$ & $118.5(3)$ \\
\hline O1-V1-O1a ${ }^{[a]}$ & $72.78(12)$ & \\
\hline O2-V1-O3 & $114.87(17)$ & $113.25(19)$ \\
\hline O2-V1-O1a ${ }^{[a]}$ & $87.31(12)$ & \\
\hline O3-V1-O1a ${ }^{[a]}$ & $83.69(9)$ & \\
\hline Dihedral Angles & & \\
\hline Aph-Bph & $87.6(2)$ & $58.3(2)$ \\
\hline
\end{tabular}

$[a]-x+1 / 2,-y+1 / 2+2,-z+1$ 
Table 3. ${ }^{51} \mathrm{~V}$ NMR date for $\mathrm{VO}\left(\mathrm{O}^{i} \mathrm{Pr}\right)_{3}, \mathbf{1}$, and $\mathbf{2}$ in $\mathrm{CD}_{2} \mathrm{Cl}_{2}$.

\begin{tabular}{llll} 
& $\mathrm{VO}\left(\mathrm{O}^{\prime} \mathrm{Pr}\right)_{3}$ & $\mathbf{1}$ & $\mathbf{2}$ \\
\hline$\delta(\mathrm{ppm})$ & $-625^{\text {[a] }}$ & -389 & -121 \\
\hline
\end{tabular}

[a] Reference 11

This weakened $\mathrm{V}(1)-\mathrm{N}(1)$ bond caused somewhat shorter $\mathrm{N}(1)$ $\mathrm{N}(2)$ distance compared with that of 1 , resulting in the multiplebond character in the $\mathrm{N}(1)-\mathrm{N}(2)$ bond of 2 . The lone pair of electrons in a nitrogen $\mathrm{p}$ orbital of the $\mathrm{V}-\mathrm{N}$ bond seems to interact with the metal $\pi$ acceptor orbitals in the case of 1 . The apical coordination trans to the vanadium hydrazido moiety was found to influence the vanadium hydrazido structure. A dihedral angles between the least-squares plane of the benzene ring and the plane of $\mathrm{C}\left(\right.$ ipso) $-\mathrm{N}(2)-\mathrm{N}(1)$ are $35.3(2)$ and $26.4(2)^{\circ}$, respectively, indicating the weak $\pi$ conjugation, wherein the $\mathrm{C}($ ipso)- $\mathrm{N}(2)$ bond distances are 1.425(7) and 1.420(8) $\AA$, respectively. A dihedral angle between the least-squares planes of the benzene rings Aph and Bph is $58.3(2)^{\circ}$. Furthermore, compared with $\mathrm{N}(1)-\mathrm{N}(2)$ distance of (dimethylhydrazido)vanadium $(\mathrm{V})$ nitrilotriethoxide $(1.311(7) \AA),{ }^{[8]}$ the longer $\mathrm{N}(1)-\mathrm{N}(2)$ distance of 2 was observed probably due to the $\pi$ conjugation. In the crystal packing, meta hydrogen atom of the benzene ring Aph is almost facing the $\pi$ electrons of the benzene ring Bph of the neighboring molecule. The distance between the hydrogen atom and the benzene ring is $3.0 \AA$, suggesting $\mathrm{CH}-\pi$ interaction to form the dimeric structure. (Figure 2b).

${ }^{51} \mathrm{~V}$ NMR measurements were demonstrated to clarify the electronic effect of alkoxide ligands on the vanadium metal (Table $3)$. In the ${ }^{51} \mathrm{~V}$ NMR spectrum of $\mathrm{VO}\left(\mathrm{O}^{\prime} \mathrm{Pr}\right)_{3},{ }^{51} \mathrm{~V}$ chemical shift was reported to be $-625 \mathrm{ppm} .{ }^{[11]}$ Compared with $\mathrm{VO}\left(\mathrm{O}^{\prime} \mathrm{Pr}\right)_{3}$, the (diphenylhydrazido)vanadium $(\mathrm{V})$ triisopropoxide (1) was observed at the lower field of $-389 \mathrm{ppm}$. The formation of imido bond led to the lower field shift in ${ }^{51} \mathrm{~V}$ NMR spectra as reported by Maatta's group. ${ }^{[12]}$ The introduction of nitrilotriethoxide ligand into the (diphenylhydrazido)vanadium $(\mathrm{V})$ compound was found to cause the lower field shift of ${ }^{51} \mathrm{~V}$ chemical shift as observed at $121 \mathrm{ppm}$ in the ${ }^{51} \mathrm{~V}$ NMR spectrum of 2 . This result is likely to be due to the apical coordination of the nitrilotriethoxide nitrogen. This lower field shift of ${ }^{51} \mathrm{~V}$ chemical shift is supported by the result of the oxidovanadium $(\mathrm{V})$ compounds by the introduction of the nitrilotriethoxide ligand. ${ }^{[13]}$ The apical coordination was found to be a key facyor in the control of the hydrazido structure and the electronic environment of the vanadium metal.

\section{Conclusions}

In conclusion, design and structural characterization of (diphenylhydrazido)vanadium $(\mathrm{V})$ compounds were performed to gain insight into the structural properties of vanadium-nitrogen multiple bond and self-assembling properties. The nitrogen of the $\mathrm{V}-\mathrm{N}$ bond is suggested to have an sp-hybridized character by the X-ray crystallographic analyses of
(diphenylhydrazido)vanadium(V)

compounds.

The (diphenylhydrazido)vanadium(V) triisopropoxide was demonstrated to dimerize through the $\mu$-isopropoxido-bridging The apical coordination of the nitrogen of $2,2^{\prime}, 2$ "-nitrilotriethoxide ligand to vanadium metal was found to lengthen the $\mathrm{V}-\mathrm{N}$ bond and cause the multiple-bond character in the N-N bond in the (diphenylhydrazido)vanadium( $(\mathrm{V})$ nitrilotriethoxide although the lone pair of electrons in a nitrogen $\mathrm{p}$ orbital of the $\mathrm{V}-\mathrm{N}$ bond appears to interact with the metal $\pi$ acceptor orbitals in the (diphenylhydrazido)vanadium( $\mathrm{V})$ isopropoxide. Another interesting structural features of (diphenylhydrazido)vanadium( $(\mathrm{V})$ compounds are their self-assembling structures through $\mathrm{CH}-\pi$ interactions. Studies on the application of the (hydrazido)vanadium(V) compounds for catalysis are now in progress.

\section{Supporting Information Summary}

Experimental procedures and characterization data for the compounds $\mathbf{1}$ and $\mathbf{2}$ are available in the Supporting Information. Crystallographic data for $\mathbf{1}$ and $\mathbf{2}$ have been deposited with the Cambridge Crystallographic Data Centre as supplementary publication no. CCDC-1443490 for 1 and CCDC-1443491 for 2.

\section{Acknowledgements}

This work was supported by ACT-C, JST. Thanks are due to the Analytical Center, Graduate School of Engineering, Osaka University.

Keywords: hydrazido compound $\cdot$ vanadium(V) compound • metal-nitrogen multiple bond $\bullet$ self-association $\bullet$ crystal structure

[1] a) C. J. Pickett, G. J. Leigh, J. Chem. Soc., Chem. Commun. 1981, 10331035; b) P. J. Walsh, M. J. Carney, R. G. Bergman, J. Am. Chem. Soc. 1991, 113, 6343-6345; c) M. M. Baum, E. H. Smith, J. Chem. Soc., Perkin Trans. 1 1993, 2513-2519; d) H. Seino, Y. Ishii, M. Hidai, J. Am. Chem. Soc. 1994, 116, 7433-7434; e) H. Seino, Y. Ishii, T. Sasagawa, M. Hidai, J. Am. Chem. Soc. 1995, 117, 12181-12193; f) H. Seino, Y. Ishii, M. Hidai, Inorg. Chem. 1997, 36, 161-171; g) C. Cao, Y. Shi, A. L. Odom, Org. Lett. 2002, 4, 2853-2856; h) Y. Li, Y. Shi, A. L. Odom, J. Am. Chem. Soc. 2004, 126, 1794-1803; i) A. Tillack, H. Jiao, I. Garcia Castro, C. G. Hartung, M. Beller, Chem. Eur. J. 2004, 10, 2409-2420; j) A. L. Odom, Dalton Trans. 2005, 225-233; k) J. D. Selby, C. D. Manley, M. Feliz, A. D. Schwarz, E. Clot, P. Mountford, Chem. Commun. 2007, 4937-4939; I) H. Herrmann, J. Lloret Fillol, H. Wadepohl, L. H. Gade, Angew. Chem. Int. Ed. 2007, 46, 8426-8430; m) D. J. Mindiola, Angew. Chem. Int. Ed. 2008, 47, $1557-$ 1559; n) M. Yuki, Y. Miyake, Y. Nishibayashi, Organometallics 2009, 28 , 5821-5827; o) Z. Huang, J. Zhou, J. F. Hartwig, J. Am. Chem. Soc. 2010, 132, 11458-11460; p) T. Gehrmann, J. Lloret Fillol, S. A. Scholl, H. Wadepohl, L. H. Gade, Angew. Chem. Int. Ed. 2011, 50, 5757-5761; q) A. D. Schwarz, C. S. Onn, P. Mountford, Angew. Chem. Int. Ed. 2012, 51, 12298-12302; r) S. A. DiFranco, R. J. Staples, A. L. Odom, Dalton Trans. 2013, 42, 2530-2539; s) J. Unruangsri, H. Morgan, A. D. Schwarz, A. D. Schofield, P. Mountford, Organometallics 2013, 32, 3091-3107; t) T. Gehrmann, J. Lloret Fillol, H. Herrmann, H. Wadepohl, L. H. Gade, Organometallics 2013, 32, 3877-3889. 
[2] K. H. Thompson, J. H. McNeill, C. Orvig, Chem. Rev. 1999, 99, $2561-$ 2572.

[3] a) D. Rehder, Angew. Chem. Int. Ed. Engl. 1991, 30, 148-167; b) A Butler and J. V. Walker, Chem. Rev. 1993, 93, 1937-1944; c) A. Butler Coord. Chem. Rev. 1999, 187, 17-35; d) A. G. J. Ligtenbarg, R. Hage, B. L. Feringa, Coord. Chem. Rev. 2003, 237, 89-101; e) D. C. Crans, J. J. Smee, E. Gaidamauskas, L. Yang, Chem. Rev. 2004, 104, 849-902; f) J. Hartung, Y. Dumont, M. Greb, D. Hach, F. Köhler, H. Schulz, M. Časný, D. Rehder, H. Vilter, Pure Appl. Chem. 2009, 81, 1251-1264; g) K. Kikushima, T. Moriuchi, T. Hirao, Tetrahedron 2010, 66, 6906-6911; h) T. Moriuchi, T. Hirao, Bioinspired Catalytic Bromination Systems for Bromoperoxidase. In Vanadium: Biochemical and Molecular Biological Approaches; H. Michibata, Ed., Springer-Verlag: Berlin, 2012; pp 127142.

[4] a) N. Wiberg, H.-W. Häring, G. Huttner, P. Friedrich, Chem. Ber. 1978, 111, 2708-2715; b) J. Bultitude, L. F. Larkworthy, D. C. Povey, G. W. Smith, J. R. Dilworth, G. J. Leigh, J. Chem. Soc., Chem. Commun. 1986, 1748-1750; c) C. Le Floc'h, R. A. Henderson, D. L. Hughes, R. L. Richards, J. Chem. Soc., Chem. Commun. 1993, 175-176; d) S. C. Davies, D. L. Hughes, Z. Janas, L. Jerzykiewicz, R. L. Richards, J. R. Sanders, P. Sobota, Chem. Commun. 1997, 1261-1262; e) R. A. Henderson, Z. Janas, L. B. Jerzykiewicz, R. L. Richards, P. Sobota, Inorg Chim. Acta 1999, 285, 178-183; f) S. C. Davies, D. L. Hughes, Z. Janas, L. B. Jerzykiewicz, R. L. Richards, J. R. Sanders, J. E. Silverston, P Sobota, Inorg. Chem. 2000, 39, 3485-3498; g) S. C. Davies, D. L. Hughes, M. Konkol, R. L. Richards, J. R. Sanders, P. Sobota, J. Chem Soc., Dalton Trans. 2002, 2811-2814; h) S. Banerjee, A. L. Odom, Dalton Trans. 2008, 2005-2008; i) T. Moriuchi, K. Ikeuchi, T. Hirao, Dalton Trans. 2013, 42, 11824-11830.

[5] a) G.R. Desiraju, Crystal Engineering: The Design of Organic Solids, Elsevier, Amsterdam, 1989; b) Perspectives in Supramolecular Chemistry: The Crystal as a Supramolecular Entity, ed. G.R. Desiraju, Wiley, Chichester, 1996; c) D. Braga, F. Grepioni, G.R. Desiraju, Chem. Rev. 1998, 98, 1375-1406; d) M. Nishio, CrystEngComm 2004, 6, $130-$ 158; e) G.R. Desiraju, J. Am. Chem. Soc. 2013, 135, 9952-9967.
[6] a) G. F. Swiegers, T. J. Malefetse, Chem. Rev. 2000, 100, 3483-3538 b) W.-Y. Sun, M. Yoshizawa, T. Kusukawa, M. Fujita, Curr. Opin. Chem Biol. 2002, 6, 757-764; c) K. Tanaka, M. Shionoya, Coord. Chem. Rev. 2007, 251, 2732-2742; d) S. Horike, S. Shimomura, S. Kitagawa, Nat Chem. 2009, 1, 695-704; e) R. S. Forgan, J. P. Sauvage, J. F. Stoddart, Chem. Rev. 2011, 111, 5434-5464

[7] a) D. D. Devore, J. D. Lichtenhan, F. Takusagawa, E. A. Maatta, J. Am. Chem. Soc. 1987, 109, 7408-7416; b) M. Lutz, H. Hagen, A. M. M. Schreurs, A. L. Spek, G. van Koten, Acta Cryst. 1999, C55, 1636-1639; c) T. Moriuchi, K. Ishino, T. Hirao, Chem. Lett. 2007, 1486-1487; d) T. Moriuchi, K. Ishino, T. Beppu, M. Nishina, T. Hirao, Inorg. Chem. 2008 47, 7638-7643; e) T. Moriuchi, T. Hirao, Pure Appl. Chem. 2009, 81, 1187-1195; f) M. Nishina, T. Moriuchi, T. Hirao, Dalton Trans. 2010, 39, 9936-9940; g) T. Moriuchi, T. Hirao, Coord. Chem. Rev. 2011, 255, 2371 2377; h) M. Nishina, T. Moriuchi, T. Hirao, Bull. Chem. Soc. Jpn. 2012 85, 606-612.

[8] T. Sakuramoto, T. Moriuchi, T. Hirao, J. Inorg. Biochem. 2016, 164, 7781.

[9] T. Moriuchi, M. Nishina, T. Hirao, Angew. Chem. Int. Ed. 2010, 49, 8386.

[10] The structural parameter $T_{5}=(\beta-\alpha) / 60$ for the coordination geometry of the five-coordinated complex proposed by Addison and Reedijik where $\beta$ and $\alpha$ represent two basal angles $(\beta>\alpha)$. The parameters for an ideal square pyramidal and trigonal bipyramidal geometries are $\tau_{5}=0(\alpha=\beta=$ $\left.180^{\circ}\right)$ and $\tau_{5}=1\left(\alpha=120^{\circ}\right.$ and $\left.\beta=180^{\circ}\right)$, respectively. A. W. Addison, T. N. Rao, J. Reedijk, J. van Rijn, G. C. Verschoor, J. Chem. Soc. Dalton Trans. 1984, 1349-1356.

[11] Y. Ji, T. Benkovics, G. L. Beutner, C. Sfouggatakis, M. D. Eastgate, D. G. Blackmond, J. Org. Chem. 2015, 80, 1696-1702.

[12] D. D. Devore, J. D. Lichtenhan, F. Takusagawa, E. A. Maatta, J. Am Chem. Soc. 1987, 109, 7408-7416.

[13] D. C. Crans, H. Chen, O. P. Anderson, M. M. Miller, J. Am. Chem. Soc. 1993, 115, 6769-6776 
Entry for the Table of Contents (Please choose one layout)

\section{FULL PAPER}
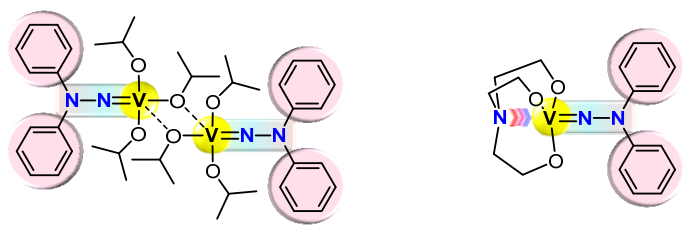

(Diphenylhydrazido)vanadium( $(\mathrm{V})$ triisopropoxide was present as a $\mu$-isopropoxidobridging dimeric structure with a distorted trigonal-bipyramidal geometry in a solid state, being in contrast to (diphenylhydrazido)vanadium $(V)$ nitrilotriethoxide possessing a pseudo trigonal-bipyramidal geometry. Another interesting structural features of (diphenylhydrazido)vanadium( $(\mathrm{V})$ compounds are their self-assembling structures through $\mathrm{CH}-\pi$ interactions.
Hydrazido Compound • SelfAssociation

Takashi Sakuramoto, Toshikazu Hirao, * and Toshiyuki Moriuchi*

Page No. - Page No.

Structural Characterization of (Diphenylhydrazido)vanadium(V) Compounds 